\title{
Machinability Study of Hybrid Nanoclay-Glass Fibre Reinforced Polyester Composites
}

\author{
P. Prabhu, ${ }^{1,2}$ P. Jawahar, ${ }^{3}$ M. Balasubramanian, ${ }^{4}$ and T. P. Mohan ${ }^{5}$ \\ ${ }^{1}$ Department of Mechanical Engineering, Bharath University, Chennai 600073, India \\ ${ }^{2}$ Department of Mechanical Engineering, DMI College of Engineering, Chennai 600123, India \\ ${ }^{3}$ Department of Production Engineering, Velammal Engineering College, Chennai 600066, India \\ ${ }^{4}$ Department of Metallurgical and Materials Engineering, Indian Institute of Technology-Madras, Chennai 600036, India \\ ${ }^{5}$ Composite Research Group, Department of Mechanical Engineering, Durban University of Technology, Durban 4001, South Africa
}

Correspondence should be addressed to P. Jawahar; dr.p.jawahar@gmail.com

Received 14 February 2013; Revised 25 June 2013; Accepted 1 July 2013

Academic Editor: Wen Shyang Chow

Copyright (C) 2013 P. Prabhu et al. This is an open access article distributed under the Creative Commons Attribution License, which permits unrestricted use, distribution, and reproduction in any medium, provided the original work is properly cited.

Glass fibre reinforced polyester composites (GRP) and hybrid nanoclay and glass fibre reinforced polyester nanocomposites (CGRP) are fabricated by vacuum assisted resin infusion technique. The optimum mechanical properties are obtained for CGRP with 3 wt.\% nanoclay. Three types of drills (carbide twist drill D 5407060, HSS twist drill BS-328, and HSS end mill (4 flutes "N"-type end mill RH-helical flute)) of $6 \mathrm{~mm}$ diameters are used to drill holes on GRP and CGRP. Three different speeds (600, 852, and 1260 rpm) and two different feeds $(0.045,0.1 \mathrm{~mm} / \mathrm{rev})$ are selected as process parameters. The effect of process parameter on thrust force and delamination during drilling CGRP is analyzed for optimizing the machining parameters. The delamination factor is low for the optimum process parameter (feed $=0.1 \mathrm{~mm} / \mathrm{rev}$ and speed $852 \mathrm{rpm}$ ). Microstructural analysis confirms that at higher feeds, delamination is low for CGRP drilled with carbide tools. In order to analyze the effect of nanoclay in CGRP on tool wear, 200 holes were drilled on CGRP samples with 3 wt.\% nanoclay, and the tool wear is analyzed under optimized parametric condition. Tool wear is high in HSS twist drill compared with carbide drill. The presence of nanoclay also accelerates the tool wear.

\section{Introduction}

Thermoset unsaturated polyester properties are improved significantly by incorporation of nanoclay particles [1-3]. Our findings also confirm that the incorporation of nanoclay in unsaturated polyester has improved the mechanical, thermal, barrier, and tribological properties of unsaturated isophthalic polyester resin $[4,5]$. In continuation of this research, we found that the incorporation of nanoclay in polyester matrix of glass fibre reinforced polyester composites has improved its mechanical properties significantly [6]. These composites may find potential application in domestic, structural, automotive, and aerospace industries as it may be a substitute for conventional glass fibre reinforced polyester composites. Hybrid clay and glass fibre reinforced polyester composites possess significant mechanical properties compared with conventional glass fibre reinforced polyester composites. These composites materials may put in industrial application either directly by casting the compound to near net shape by hand layup process, vacuum assisted resin infusion technique, or by using sophisticated techniques. However, it needs some fine secondary machining to fasten it in counter parts to meet the final requirements. Drilling is the main operation to make holes for screws, bolts, or rivets assemblies in composite structures used in the automotive and aircraft industries. Lots of the literatures available on machining of fibre reinforced polymer composites [7-12]. Unfortunately, no literature is available on machining of hybrid clay and glass fibre reinforced polyester nanocomposites. The presence of nanoclay in the polymer matrix may also attribute to the rise in cutting forces, delamination, and tool wear.

Keeping this into consideration, in this current work, hybrid nanoclay and glass fibre reinforced polyester nanocomposites (CGRP) and conventional glass fibre reinforced polyester composites (GRP) are fabricated by vacuum assisted resin infusion technique. The CGRP with optimum 
mechanical properties is selected and subjected to further machining studies.

Three types of drills (carbide twist drill D 5407060, HSS twist drill BS-328 and HSS end mill (4 flutes "N"-type end mill RH-helical flute)) of $6 \mathrm{~mm}$ diameters are used to drill holes on GRP and CGRP. Three different speeds (600, 852, and $1260 \mathrm{rpm})$ and two different feeds $(0.045,0.1 \mathrm{~mm} / \mathrm{rev})$ are selected as process parameters. The effect of process parameter on thrust force and delamination is analyzed. The tool wear during machining CGRP coupons will also be analyzed. The optimum machining parameter for better machining and better tool life will also be identified by this technical work.

\section{Experimental Procedure}

2.1. Materials. The unsaturated isophthalic polyester resin (IP) used for matrix system is ISO-4503 procured from Vasavibala Resins (P) Ltd., Chennai (viscosity: 500-600 cps, acid value: $15-19$, gel time: $15-25 \mathrm{~min}$, and heat deflection temperature: $95^{\circ} \mathrm{C}$ ). Catalyst used is methyl ethyl ketone peroxide (MEKP), and accelerator used is cobalt naphthenate procured from Mahaveer Chemicals, Chennai.

The inorganic clay (UBC) used is bentonite, a mined montmorillonite clay with $\mathrm{pH}$-value of 9-10.5, and cation exchange capacity $90 \mathrm{meq} / 100 \mathrm{~g}$ procured from Emerck (India) Pvt. Ltd., Mumbai. This inorganic clay is hydrophilic in nature and hence not compatible with organic polymers for preparing clay-polymer nanocomposites. In order to increase the swelling properties of bentonite, sodium activation was performed as reported elsewhere [1]. The clay was then treated with dodecylamine to yield hydrophobic organoclay as reported elsewhere [13].

E-glass fibres are used as the reinforcement for conventional glass fibre reinforced polyester composites (GRP) and for hybrid clay and glass fibre reinforced polyester composites (CGRP). Bidirectional woven roving mat (WRM) of areal density of 610 GSM is obtained from Saint-Gobain Vetrotex India Ltd.

2.2. Nanocomposite Processing Methodology. The preparation of hybrid clay and glass fibre reinforced polyester nanocomposites (CGRP) involves the dispersion of different amounts $(1,2,3,4$, and 5 wt.\%) of organomodified clay (OMC) in the polyester resin by high-shear mixing at an optimized speed of $1000 \mathrm{rpm}$ for $1 \mathrm{~h}$. Laminates with 6 layered glass fibre woven roving mat $(35 \mathrm{~cm} \times 35 \mathrm{~cm})$ were stacked in order on work table and were vacuumed to a fixed vacuum pressure of $25 \mathrm{kPa}$. Methyl ethyl ketone peroxide catalyst and cobalt naphthenate accelerator were added to the resin to initiate the curing reaction. Nanoclay-resin mixture is infused in the glass fibre under fixed vacuum pressure. The laminates were allowed to cure under vacuum for $12 \mathrm{~h}$ under room temperature. The laminates were taken and postcured at $70^{\circ} \mathrm{C}$ for $3 \mathrm{hrs}$. Similarly, glass fibre reinforced polyester composite (GRP) is prepared in the same manner without addition of nanoclay in the polyester mix by vacuum assisted resin infusion technique. The composition of various composites is given in Table 1. Samples were cut for required dimension to
TABLE 1: Composition of GRP and CGRP samples.

\begin{tabular}{lcc}
\hline Samples specification & Matrix & Reinforcement \\
\hline GRP & Polyester & $50 \mathrm{wt} . \% \mathrm{WRM}$ \\
CGRP (1\% OMC) & Polyester & $50 \mathrm{wt} \%$ WRM + 1 wt.\% OMC \\
CGRP (2\% OMC) & Polyester & $50 \mathrm{wt} \%$ WRM + 2 wt.\% OMC \\
CGRP (3\% OMC) & Polyester & $50 \mathrm{wt} \%$ WRM + 3 wt.\% OMC \\
CGRP (4\% OMC) & Polyester & $50 \mathrm{wt} \%$ WRM + 4 wt.\% OMC \\
CGRP (5\% OMC) & Polyester & $50 \mathrm{wt} . \% \mathrm{WRM} \mathrm{+} \mathrm{5} \mathrm{wt. \%} \mathrm{OMC}$ \\
\hline
\end{tabular}

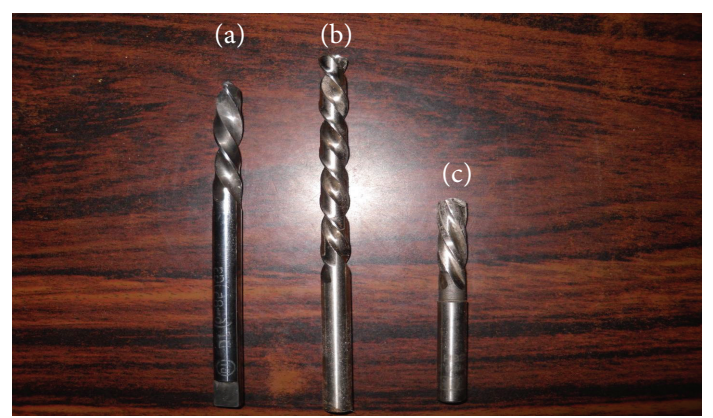

FIGURE 1: Tool used for machining. (a) Carbide D 5407060, (b) HSS twist drill (HSS-ORD, BS-328), and (c) HSS end mill (4 FLUTES "N"-type end mill RH-helical flute).

perform tensile studies. The CGRP with optimized mechanical properties is considered for further machining studies.

2.3. Mechanical Testing. The tensile test was carried out to find the breaking tensile strength and tensile modulus of GRP and CGRP. The tensile properties were determined using a universal tensile testing machine (FIE Pvt. Ltd., India) according to ASTM D-3039 standard.

2.4. Microstructural Analysis. Thin films of $60-90 \mathrm{~nm}$ thickness were sliced by diamond blade using Philips microtome. The sliced films were taken in copper grids for further characterization using transmission electron microscope. Transmission electron microscopic studies were conducted on CGRP samples with optimized mechanical property using transmission electron microscope (JEOL JEM 1200EX), operated at the operating voltage of $200 \mathrm{KV}$. It gives information about the dispersion of clay layers, and so it is a direct evidence for the formation of nanocomposites. Scanning electron microscopy studies were carried on CGRP samples to analyze the delamination during machining by drilling using HITACHI-S3400N scanning electron microscope.

2.5. X-Ray Diffraction (XRD). The objective of the XRD is to find the interlayer spacing of the clay. It gives information about the formation of nanocomposites. The X-ray diffraction was performed for organomodified clay (OMC), polyester filled with OMC to evaluate the degree of layer separation from the $d$-spacing. It was carried out at a scanning rate of $2^{\circ} / \mathrm{min}$ using $\mathrm{Cu}-\mathrm{K} \alpha$ radiation $(\lambda=1.5406 \AA)$. 


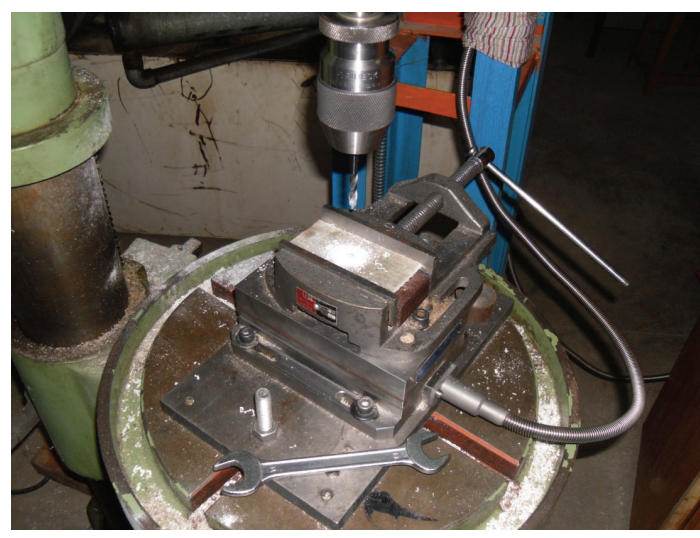

FIGURE 2: Kistler quartz three-component dynamometer (type 9257B).

2.6. Tools Used. Three different types of tools (carbide D 5407060, HSS twist drill (HSS-ORD, BS-328), and HSS end mill (4 FLUTES “N”-type end mill RH-Helical flute) are used (Figure 1). Using these tools, holes of $6 \mathrm{~mm}$ were drilled on GRP and CGRP laminates at different process parameters to study the influence of cutting tools, cutting speed, and feed on thrust force developed and on delamination.

2.7. Machining Studies. CGRP samples were taken and holes of size $6 \mathrm{~mm}$ are machined (drilled) at three different speeds $(600 \mathrm{rpm}, 852 \mathrm{rpm}$, and $1260 \mathrm{rpm})$ and two different feed rates $(0.045 \mathrm{~mm} / \mathrm{rev}$ and $0.1 \mathrm{~mm} / \mathrm{rev})$ in radial drilling machine (CKC). The thrust force during drilling GRP and hybrid CGRP is acquired using Dynoware Software with a Kistler Quartz three-component dynamometer (type 9257B) connected to the charge amplifier in Karunya University, India (Figure 2). Delamination factor is studied using profile projector (Metzer-801R). The optimum tool with optimum processing parameter will be obtained by considering the thrust force and delamination factor. 200 holes are drilled on the CGRP samples under optimized condition. The tool wear is measured using tool makers microscope in regular intervals after drilling 25 holes in succession on GRP and CGRP samples. The delamination and tool wear mechanism is analyzed by using scanning electron microscope.

\section{Results and Discussion}

3.1. Tensile Properties. The influence of organomodified clay (OMC) addition on tensile strength of hybrid composites is shown in Table 2. For each specification, five tensile samples were tested, and the aggregate of the values is presented in Table 2. The tensile strength of GRP is $214 \mathrm{MPa}$. It increases on addition of OMC. It increases to the maximum of $294 \mathrm{MPa}$ for the OMC content of $3 \mathrm{wt} . \%$ and decreases at higher weight fraction.

The increase in strength of hybrid nanocomposites suggests that the exfoliated and intercalated nanoclay platelets dispersed in polyester matrix can induce some strengthening mechanism in the matrix material. Researchers have reported that crack pinning, crack bifurcation, and so forth were some

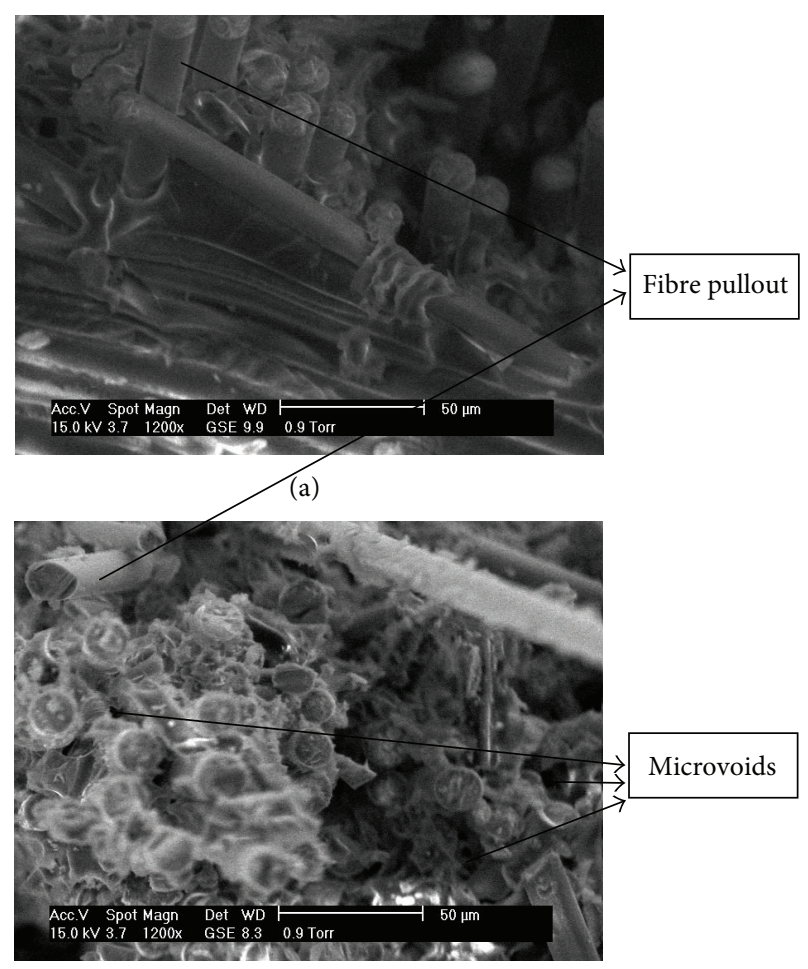

(b)

FIGURE 3: SEM micrographs of tensile fracture surface of (a) GRP, (b) CGRP with 3 wt.\% OMC.

TABLE 2: Tensile strength and tensile modulus of GRP and CGRP composites.

\begin{tabular}{lcc}
\hline Content (wt.\%) & Tensile strength (MPa) & Tensile modulus (GPa) \\
\hline GRP & $214 \pm 5.09$ & $9.5 \pm 0.3$ \\
CGRP (1\% OMC) & $225 \pm 6.5$ & $12 \pm 0.3$ \\
CGRP (2\% OMC) & $252 \pm 4.5$ & $14.2 \pm 0.5$ \\
CGRP (3\% OMC) & $294 \pm 5.7$ & $14.8 \pm 0.4$ \\
CGRP (4\% OMC) & $282 \pm 3.1$ & $16.4 \pm 0.4$ \\
CGRP (5\% OMC) & $250 \pm 5.9$ & $14.2 \pm 0.4$ \\
\hline
\end{tabular}

of the strengthening mechanisms observed in nanoparticlefilled composites for increase in strength of clay-polymer nanocomposites [1, 14-16].

The influence of nanoclay addition on tensile modulus of GRP and CGRP composites is shown in Table 2. The tensile modulus of GRP is $9.5 \mathrm{GPa}$. On addition of OMC, tensile modulus increases to $14.8 \mathrm{GPa}$ and $16.4 \mathrm{GPa}$ for the clay content of 3 and 4 wt.\%, respectively, and decreases slightly at higher weight fractions of clay. Hybrid CGRP nanocomposites exhibit better tensile property compared to GRP composites. Nearly 55\% improvement in tensile modulus is found for the CGRP with 3 wt.\% OMC. In general, the maximum value of tensile strength and compromising value of modulus are observed for the CGRP samples with $3 \mathrm{wt}$.\% nanoclay. This can be considered further for machining studies. The improvement in tensile modulus for nanocomposites was due to the exfoliated and intercalated clay platelets present in the 


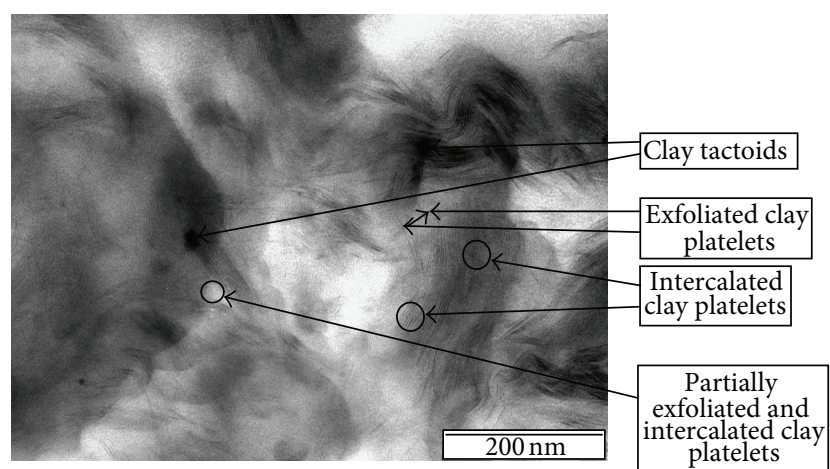

FIGURE 4: TEM micrographs for hybrid CGRP with 3 wt.\% nanoclay content.

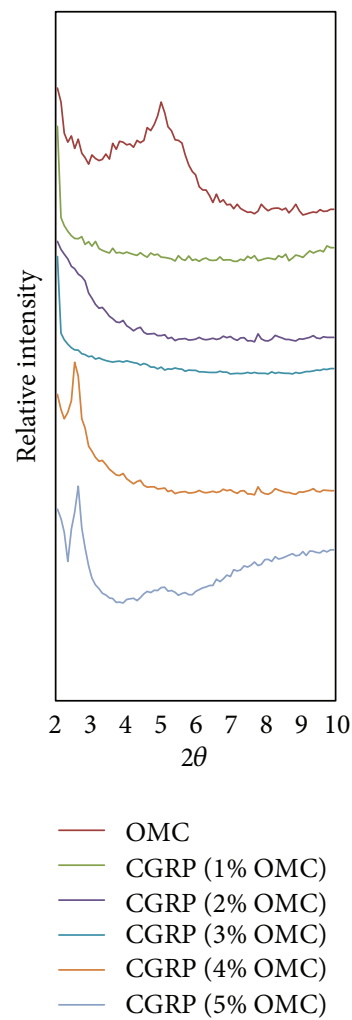

FIgURE 5: X-ray diffraction patterns of OMC and OMC-filled composites.

nanoclay modified polyester matrix. As reported earlier [5], the clay platelets restrict the mobility of polymer chains under loading and improve the modulus of matrix. The decrease in modulus and strength at higher clay content may due to the existence of clay tactoids.

Figure 3 shows the tensile fracture surface of GRP and CGRP with 3 wt.\% OMC. The fracture surface reveals that fibre pullout is the dominating mechanism of failure in GRP (Figure 3(a)). The fibre pullout confirms the poor interfacial property of matrix with the fibre. Figure 3(b) shows the tensile fracture surface of hybrid CGRP nanocomposites with 3 wt.\% OMC. Interfacial cracking is not found in the hybrid nanocomposites samples suggesting that interfacial bonding
TABLE 3: Dynamometer readings for GRP and CGRP.

\begin{tabular}{lccccc}
\hline Tool & Material & $\begin{array}{c}\text { Speed } \\
(\mathrm{RPM})\end{array}$ & $\begin{array}{c}\text { Feed } \\
(\mathrm{mm} / \mathrm{min})\end{array}$ & $\begin{array}{c}\text { Tangential } \\
\text { force }(\mathrm{N})\end{array}$ & $\begin{array}{c}\text { Thrust } \\
\text { force }(\mathrm{N})\end{array}$ \\
\hline \multirow{4}{*}{ Carbide twist } & GRP & 600 & 0.045 & 73.7 & 14.1 \\
drill & 600 & 0.1 & 93.3 & 21 \\
& CGRP & 600 & 0.045 & 91.6 & 17.9 \\
& CGRP & 600 & 0.1 & 103.6 & 23.1 \\
\hline \multirow{4}{*}{ HSS twist } & GRP & 600 & 0.045 & 294.0 & 40.3 \\
drill & GRP & 600 & 0.1 & 370.7 & 52.3 \\
& CGRP & 600 & 0.045 & 301.8 & 57.6 \\
& CGRP & 600 & 0.1 & 440.2 & 62.6 \\
\hline \multirow{4}{*}{ HSS end mill } & GRP & 600 & 0.1 & 83.2 & 42.3 \\
& GGRP & 600 & 0.045 & 116.7 & 19.7 \\
& CGRP & 600 & 0.1 & 116.0 & 30.1 \\
\hline
\end{tabular}

TABLE 4: Dynamometer readings of CGRP with $3 \mathrm{wt} . \%$ OMC.

\begin{tabular}{|c|c|c|c|c|}
\hline Tool & $\begin{array}{l}\text { Speed } \\
\text { (RPM) }\end{array}$ & $\begin{array}{c}\text { Feed } \\
(\mathrm{mm} / \mathrm{rev})\end{array}$ & $\begin{array}{l}\text { Tangential } \\
\text { force }\left(F_{z}\right) \\
\text { (N) }\end{array}$ & $\begin{array}{l}\text { Thrust } \\
\text { force }\left(F_{y}\right) \\
\text { (N) }\end{array}$ \\
\hline \multirow{6}{*}{$\begin{array}{l}\text { Carbide twist } \\
\text { drill }\end{array}$} & 600 & 0.045 & 91.6 & 17.9 \\
\hline & 600 & 0.1 & 103.6 & 23.1 \\
\hline & 852 & 0.045 & 84.4 & 24.2 \\
\hline & 852 & 0.1 & 121.6 & 20.8 \\
\hline & 1260 & 0.045 & 101.4 & 30.2 \\
\hline & 1260 & 0.1 & 123.1 & 43.5 \\
\hline \multirow{6}{*}{$\begin{array}{l}\text { HSS twist } \\
\text { drill }\end{array}$} & 600 & 0.045 & 301.9 & 57.6 \\
\hline & 600 & 0.1 & 440.2 & 62.6 \\
\hline & 852 & 0.045 & 334.1 & 68.7 \\
\hline & 852 & 0.1 & 441.7 & 63.6 \\
\hline & 1260 & 0.045 & 290.0 & 75.1 \\
\hline & 1260 & 0.1 & 445.4 & 57.7 \\
\hline \multirow{6}{*}{ HSS end mill } & 600 & 0.045 & 116.7 & 19.7 \\
\hline & 600 & 0.1 & 116.0 & 30.1 \\
\hline & 852 & 0.045 & 98.1 & 28.6 \\
\hline & 852 & 0.1 & 137.2 & 34.3 \\
\hline & 1260 & 0.045 & 115.5 & 42.4 \\
\hline & 1260 & 0.1 & 120.2 & 49.3 \\
\hline
\end{tabular}

of hybrid nanocomposites is good. However, some micropores and fibre pullouts are noticed on the fractured surface, which is not severe compared to GRP. This confirms that still there is a hope for improvement in mechanical properties by optimizing the process conditions. The fracture surface analysis also suggests that the exfoliated and intercalated clay platelets improve the interfacial property more efficiently and helps in improving the strength and modulus.

3.2. Transmission Electron Microscope (TEM) Studies. The TEM micrograph of CGRP with $3 \mathrm{wt} . \%$ nanoclay is shown in Figure 4 . The TEM micrograph confirms the formation of 


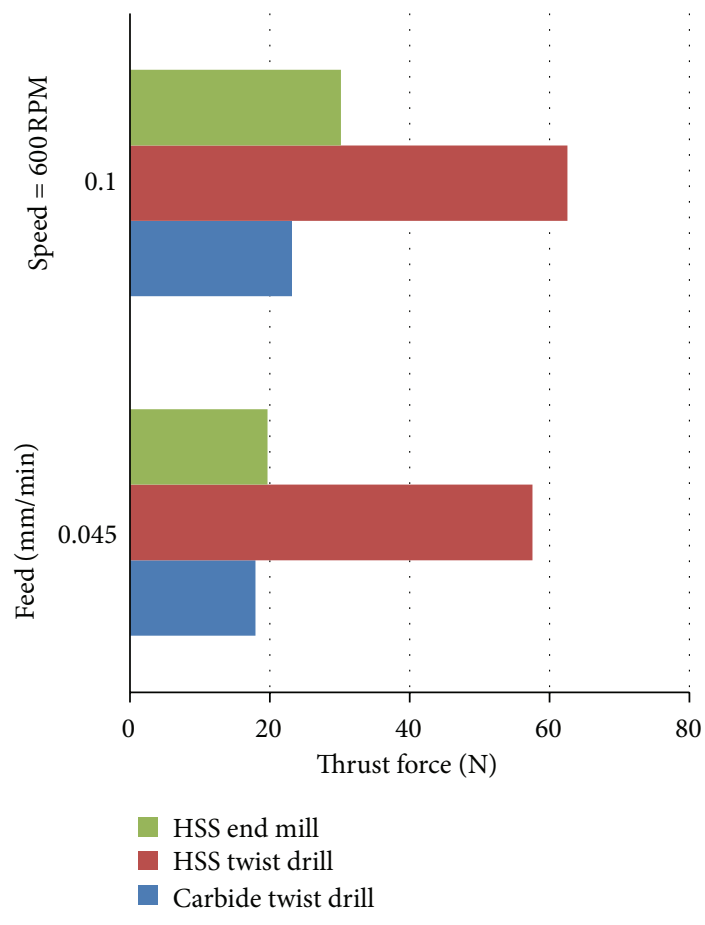

Figure 6: Correlation between feed rate and thrust force at cutting speed of $600 \mathrm{rpm}$.

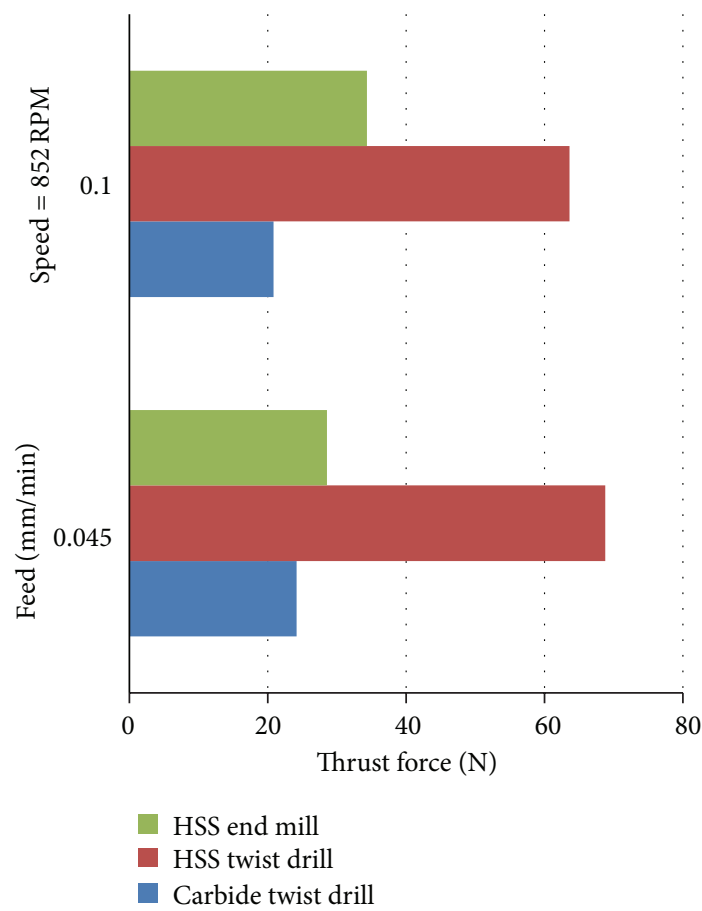

FIGURE 7: Correlation between feed rate and thrust force at cutting speed of $852 \mathrm{rpm}$.

intercalated and exfoliated nanocomposites. In hybrid CGRP, the clay is intercalated and exfoliated and confirms the dispersion of clay platelets. However, in some regions, still the presence of clay tactoids sheds light on the possibility of

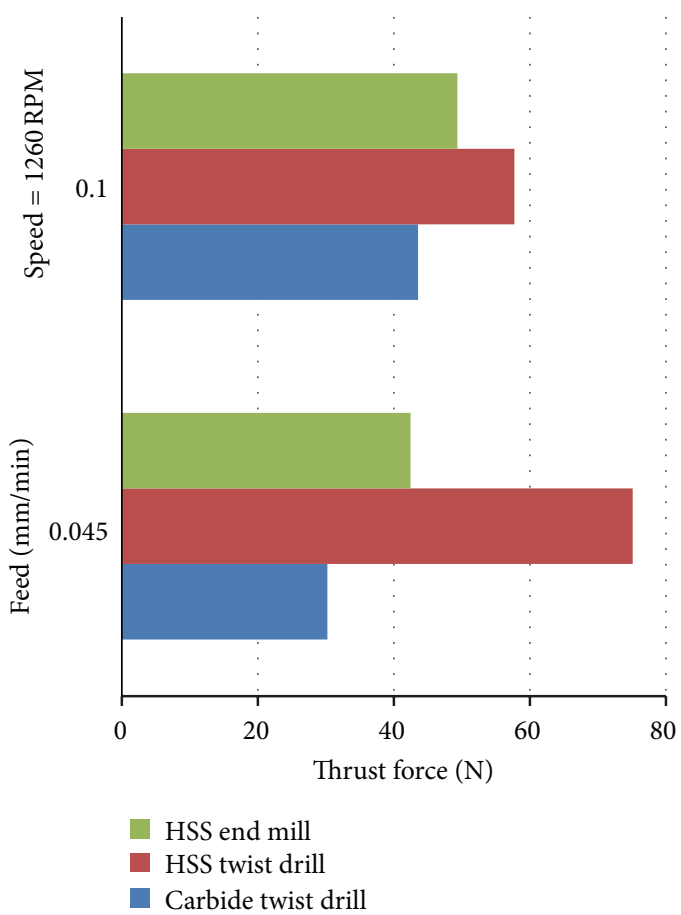

FIGURE 8: Correlation between feed rate and thrust force at cutting speed of $1260 \mathrm{rpm}$.

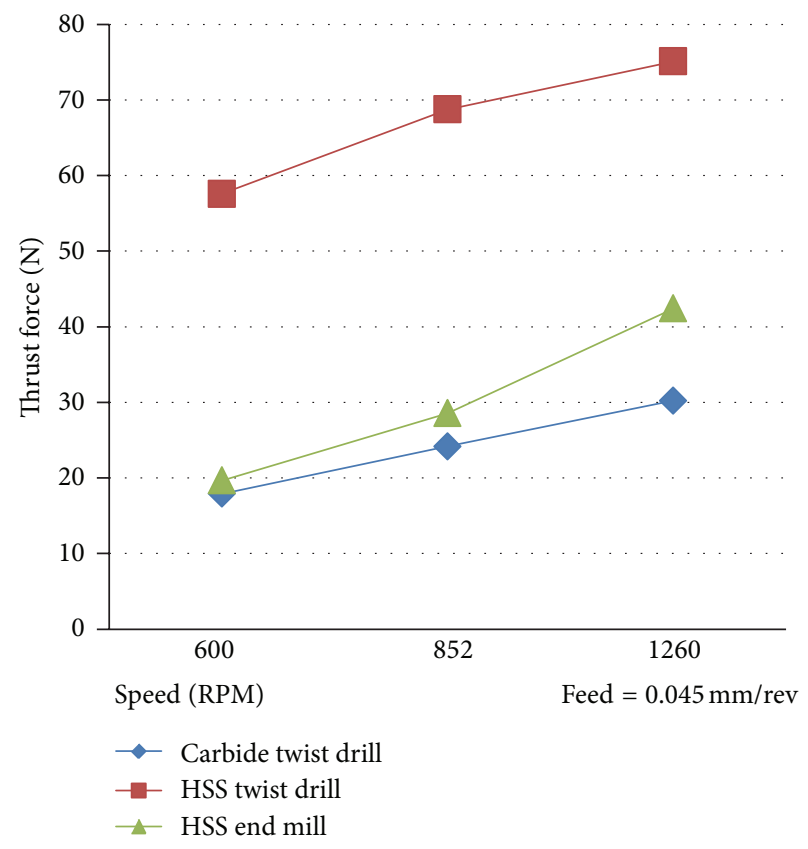

FIGURE 9: Correlation between cutting speed and thrust force at feed rate of $0.045 \mathrm{~mm} / \mathrm{rev}$.

improving the clay dispersion by optimizing the mixing and processing parameters. By optimizing the parameter, the mechanical properties can be improved to greater extent. Clay dispersion confirms the peak values of tensile strength and tensile modulus discussed earlier (Table 2). 
TABLE 5: Delamination factor for GRP and CGRP.

\begin{tabular}{lccc}
\hline Tool & $\begin{array}{c}\text { Speed } \\
(\mathrm{RPM})\end{array}$ & $\begin{array}{c}\text { Feed } \\
(\mathrm{mm} / \mathrm{rev})\end{array}$ & $\begin{array}{c}\text { Delamination } \\
\text { factor } F_{d}=D_{\max } / D\end{array}$ \\
\hline & 600 & 0.045 & 1.096 \\
Carbide twist & 600 & 0.1 & 1.036 \\
drill & 852 & 0.045 & 1.015 \\
& 852 & 0.1 & 1.01 \\
& 1260 & 0.045 & 1.166 \\
& 1260 & 0.1 & 1.111 \\
\hline HSS twist & 600 & 0.045 & 1.038 \\
drill & 600 & 0.1 & 1.111 \\
& 852 & 0.045 & 0.995 \\
& 852 & 0.1 & 1 \\
& 1260 & 0.045 & 1.063 \\
& 1260 & 0.1 & 1.176 \\
\hline & 600 & 0.045 & 1.128 \\
& 600 & 0.1 & 1.118 \\
& 852 & 0.045 & 1.123 \\
& 852 & 0.1 & 1.043 \\
& 1260 & 0.045 & 1.05 \\
& 1260 & 0.1 & 1.058 \\
\hline
\end{tabular}

Where $D_{\max }$ : Maximum diameter of the drilled hole in CGRP samples. $D$ : Diameter of the drill.

3.3. X-Ray Diffraction Studies. XRD patterns of organomodified clay (OMC) and OMC-filled composites are shown in Figure 5. The organoclay shows a sharp peak at $2 \theta$ values of $5^{\circ}$ corresponding to the 001 basal plane diffraction. The interlayer distance ( $d$-spacing) of OMC obtained from Bragg's law is $17.7 \AA$. Figure 5 shows the diffraction pattern for the polyester filled with OMC. It is observed that the 001 basal plane diffraction peak of OMC is absent in CGRP with $(1,2$, and 3 wt.\% OMC). This reveals that the interlayer distance of OMC is more than $70 \AA$ or the layers are randomly dispersed in the polymer matrix. TEM images for CGRP with $3 \mathrm{wt} . \%$ OMC have also revealed that the clay platelets are exfoliated by the intrusion of polymer molecules in the intergallery spacing of clay platelets. Also, the d-spacing seems to be in the range of $70 \AA$ to $100 \AA$.

3.4. Machining Studies. For machining studies, CGRP with optimum mechanical properties (CGRP with $3 \mathrm{wt} . \%$ nanoclay) is chosen for machining studies. A constant speed of $600 \mathrm{rpm}$ is considered to compare the influence of cutting tools on tangential force and thrust force developed during drilling holes in GRP and CGRP composites with $3 \mathrm{wt} . \%$ nanoclay (Table 3). We all know that, as feed increases, there will be always a rise in thrust force. From Table 2, it was found that for all the tools, the tangential force and thrust force increase as feed increases both for GRP and CGRP. It is in agreement with the work reported elsewhere [10, 17].

It was also found that the tangential and thrust force developed during machining CGRP is comparatively higher than the GRP. Earlier, it was also found that the strength and

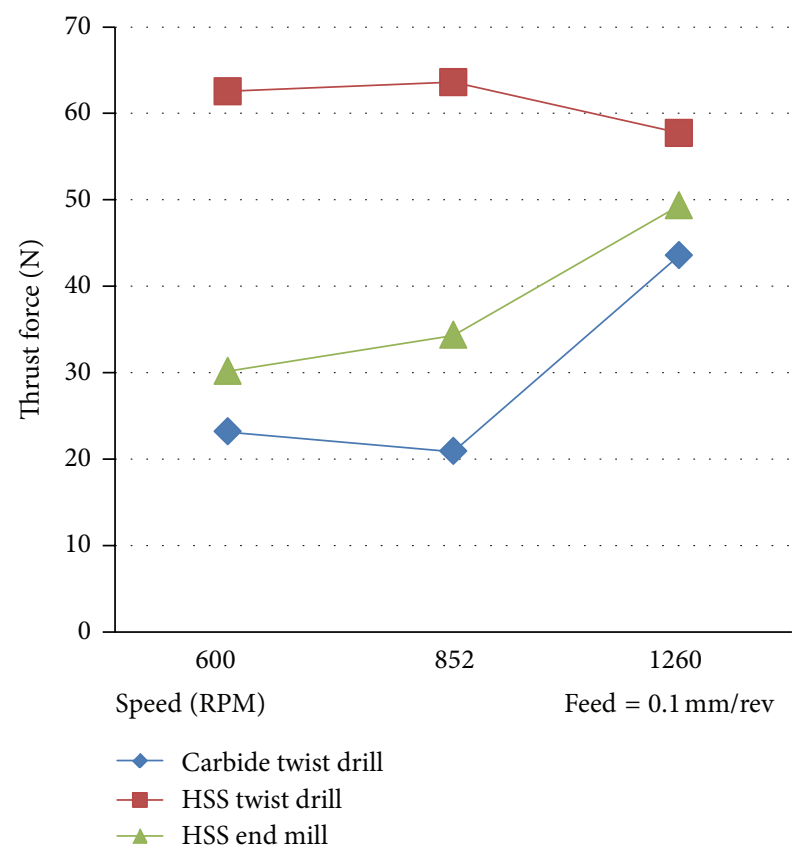

Figure 10: Correlation between cutting speed and thrust force at feed rate of $0.1 \mathrm{~mm} / \mathrm{rev}$.

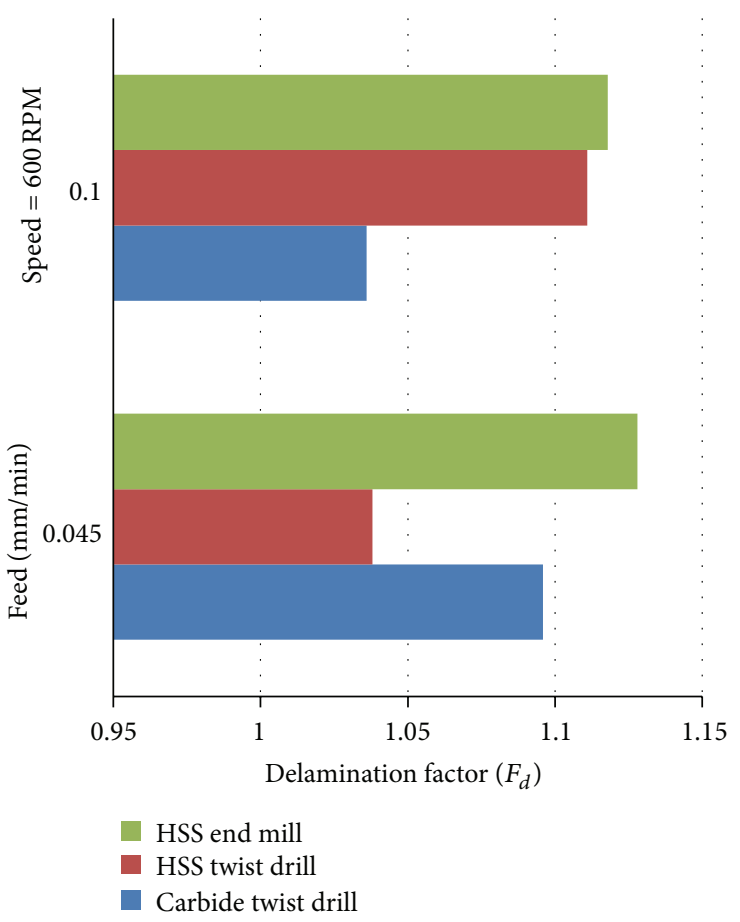

FIgURE 11: Correlation between feed rate and delamination factor at cutting speed of $600 \mathrm{rpm}$.

the modulus of CGRP is optimum and highest for CGRP with $3 \mathrm{wt} . \%$ nanoclay. The presence of well-intercalated and exfoliated nanoclay in the polyester matrix of CGRP resists cutting and thereby develops excess thrust force and tangential force to perform the cutting operations.

It was also found that the hardness of the tool also plays an important role in machining of GRP and CGRP. From 


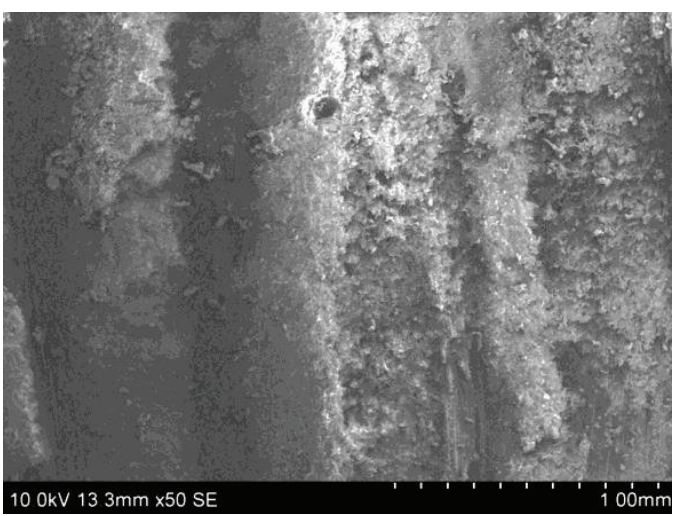

(a)

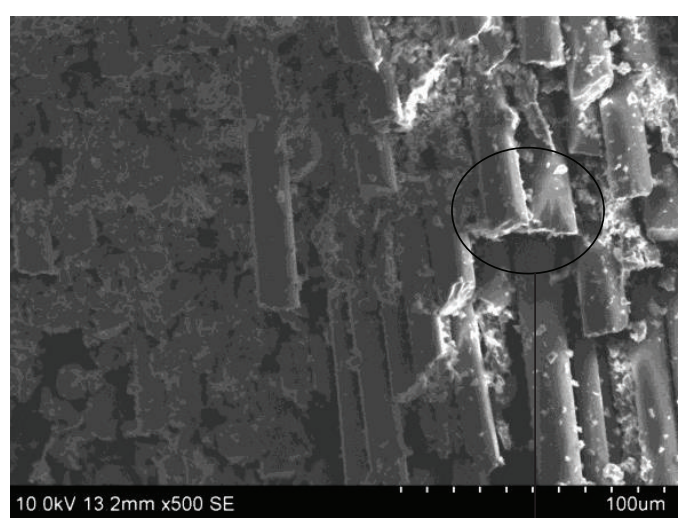

(b)

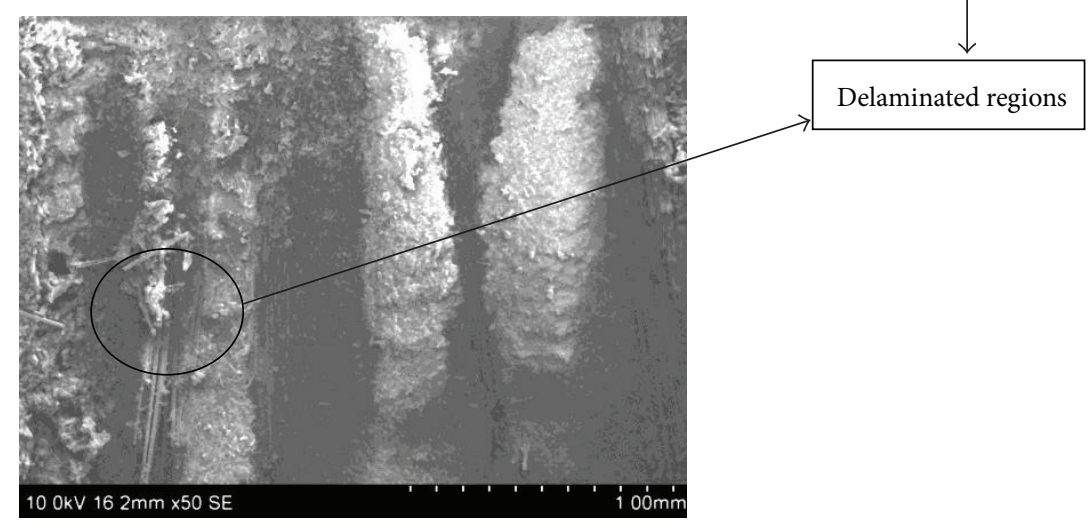

(c)

FIGURE 12: SEM pictures of machined CGRP at cutting speed of $600 \mathrm{rpm}$ and feed rate of $0.1 \mathrm{~mm} / \mathrm{rev}$. (a) Carbide twist drill, (b) HSS end mill, and (c) HSS twist drill.

Table 3, it was found that the tangential force developed during drilling is four times higher for HSS twist drill compared with Carbide twist drill. Carbide twist drill being harder can easily chop the glass fibres and nanoclay impregnated polyester matrix than HSS twist drill.

The scenario seems to be slightly different while using HSS end mill. The tangential force seems to be slightly higher or almost the same. The possible reason may be that the number of cutting edges present in end mill is four, whereas for remaining tool, it is only 2 . Hence, the tangential force and thrust force may be shared by four cutting edges and can bring down the forces acting on each cutting edge.

The first set of results here presented is concerned with influence of feed rate on thrust force at constant speed of $600 \mathrm{rpm}$ for both GRP and CGRP. At a constant cutting speed of $600 \mathrm{rpm}$ as the feed increases, the thrust force and tangential force also increase. Thus, the feed is directly proportional to thrust and tangential force as reported elsewhere [18].

In general, it was found that, the nanoclay presence in CGRP restricts the cutting forces more significantly than GRP composite materials. This resistance offered by nanoclay may increase the wear rate of the tool, irrespective of its material and its geometry. Optimum process parameter (speed, feed, and tool material) can effectively reduce the tangential and thrust forces developed during cutting and also reduces tool wear and improves tool life.

To better understand the influence of process parameters, the CGRP with 3 wt.\% nanoclay is chosen for machining, and the influence of speed, feed, and tool material on thrust force is analyzed and tabulated (Table 4).

The influence of feed rate on thrust force is shown in Figures 6,7 , and 8 , respectively, whereas two different feed rates $(0.045$ and $0.1 \mathrm{~mm} / \mathrm{rev})$ and three different cutting speeds $(600,852$, and $1260 \mathrm{rpm})$ are employed.

From Figures 6, 7, and 8, it is inferred that as feed increases the thrust force also increases for all the three tools at all the cutting speeds except for a few like the carbide tool which decreases in thrust force at the speed of $852 \mathrm{rpm}$. It is generally reported that the thrust force increases with rise in feed rate for drilling fibre reinforced polymer composites $[10,17]$.

The influence of cutting speed on thrust force of CGRP is shown in Figures 9 and 10.

From Figures 9 and 10, it is understood that as the cutting speed increases, the thrust force also increases slightly. The thrust force developed is low while drilling holes using carbide tool. HSS twist drill registers a high value of thrust force. HSS end mill cutter lies in the middle. The possible reason 


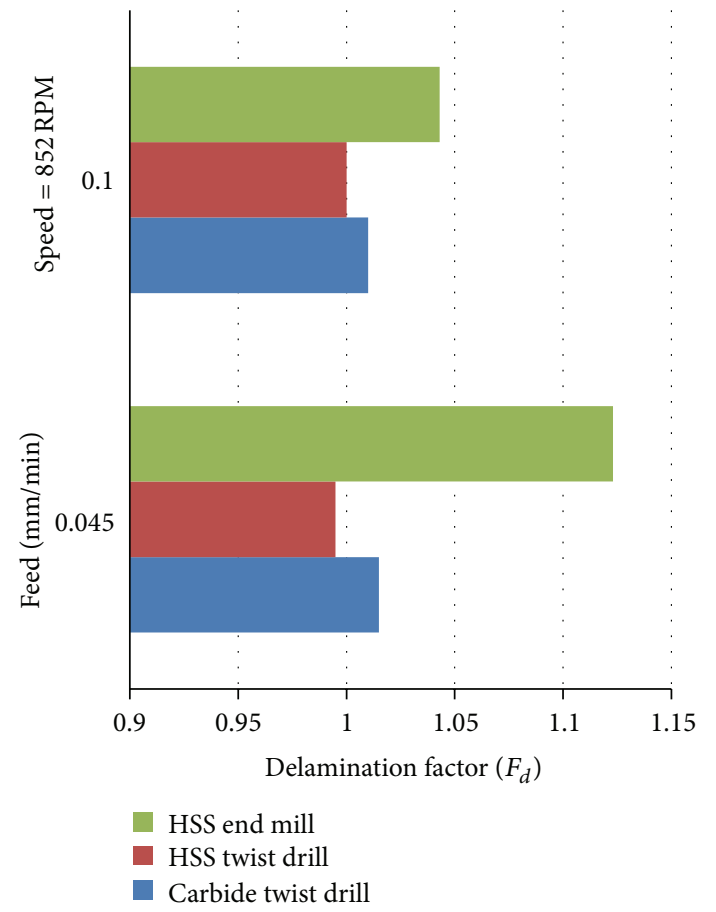

FIGURE 13: Correlation between feed rate and delamination factor at cutting speed of $852 \mathrm{rpm}$.

may be that the Carbide drill is being hard in nature compared to HSS twist drill and HSS end mill. Hence, Carbide tool can easily make indentation on CGRP composites, chops the surface, and removes the chip easily in the form of powder. From Figure 9, it was also found that as cutting speed increases, the thrust force also increases slightly for HSS tool and decreases slightly as speed rises further. The HSS end mill follows the same trend as the HSS drill. In general, it confirms that there are not much significant changes in thrust force inherited by change in cutting speed at higher feed rate for HSS end mill and Carbide drill at lower cutting speeds (600 and $852 \mathrm{rpm})$. This is in agreement with the work reported elsewhere [19]. Also, it was found that the carbide tool registers a low thrust force for cutting speed of $852 \mathrm{rpm}$ and feed rate of $0.1 \mathrm{~mm} / \mathrm{rev}$.

3.5. Studies on Delamination Factor. The CGRP is machined using different tools at different speed, and feeds. The delamination factor is measured using profile projector and tabulated in Table 5.

3.5.1. Effect of Feed on Delamination. At $600 \mathrm{rpm}$, the delamination is low while using Carbide tool and HSS twist drill compared with HSS end mill at feed rate of $0.1 \mathrm{~mm} / \mathrm{rev}$ from Figure 11. As feed increases from $0.045 \mathrm{~mm} / \mathrm{rev}$ to $0.1 \mathrm{~mm} / \mathrm{rev}$, the delamination increases for HSS twist drill, whereas for Carbide drill, it decreases significantly. The hardness of Carbide tool and presence of three cutting edges in HSS end mill may be the reason for the decrease in delamination, but for HSS end mill, still delamination is in higher side.

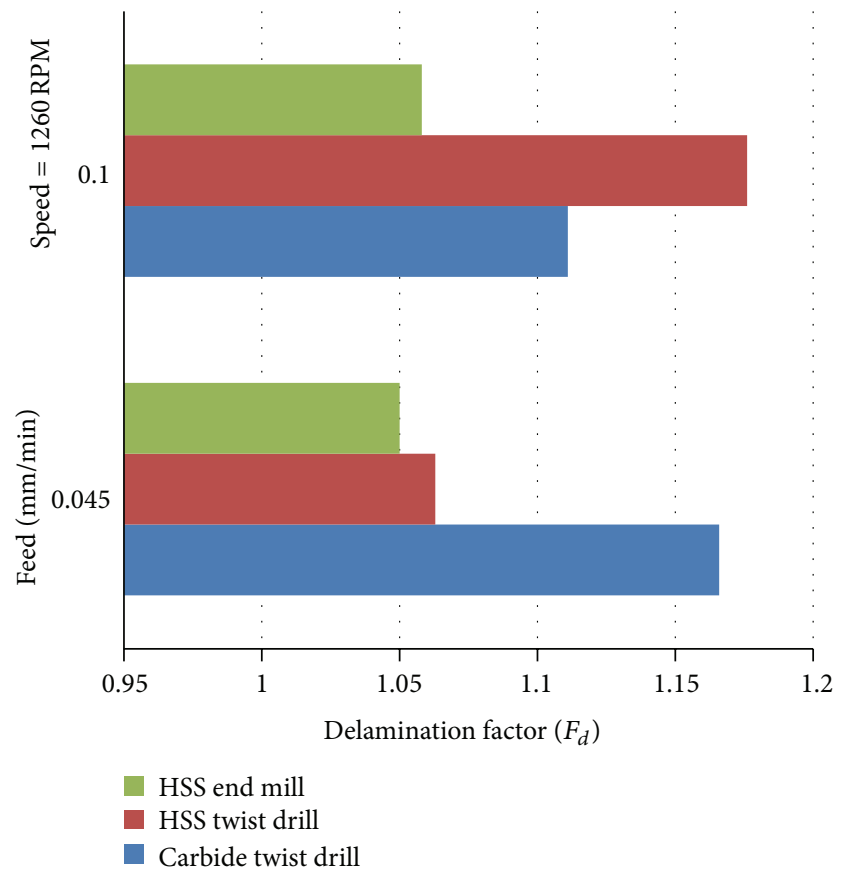

FIGURE 14: Correlation between feed rate and delamination factor at cutting speed of $1260 \mathrm{rpm}$.

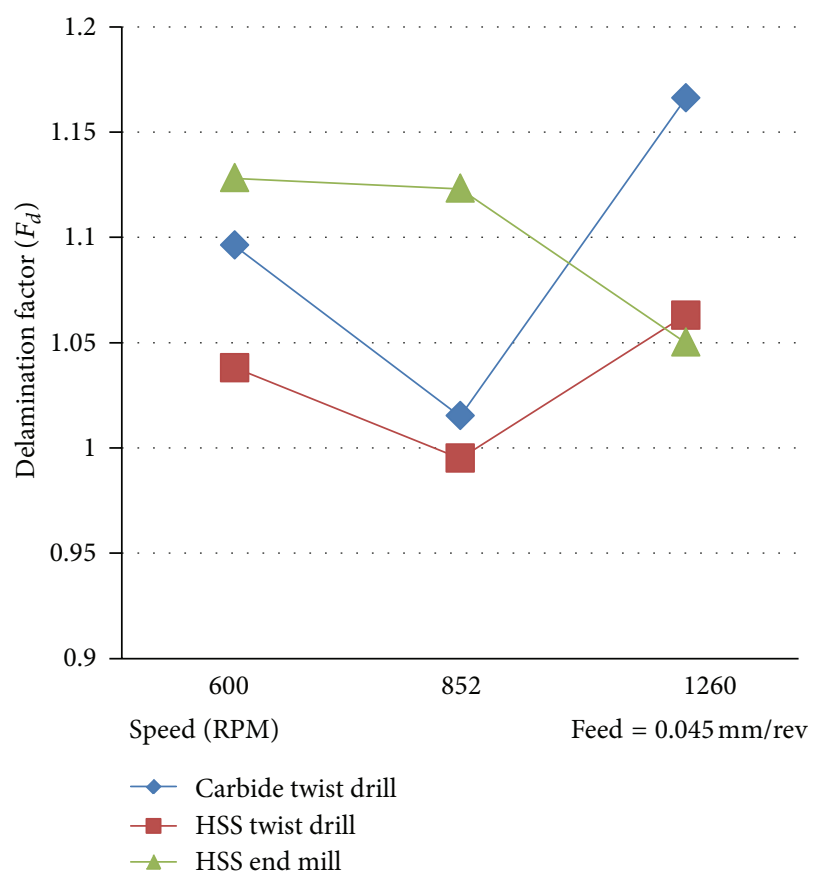

FIGURE 15: Correlation between cutting speed and delamination factor at feed rate of $0.045 \mathrm{~mm} / \mathrm{rev}$.

The delamination effect can be depicted much clearly by the scanning electron micrographs of the machined surface at the speed of $600 \mathrm{rpm}$ and at the feed of $0.1 \mathrm{~mm} / \mathrm{rev}$ (Figure 12). From Figure 12, it was understood that the surface finish was good and delamination is low for CGRP machined with Carbide twist drill, whereas for HSS twist drill 


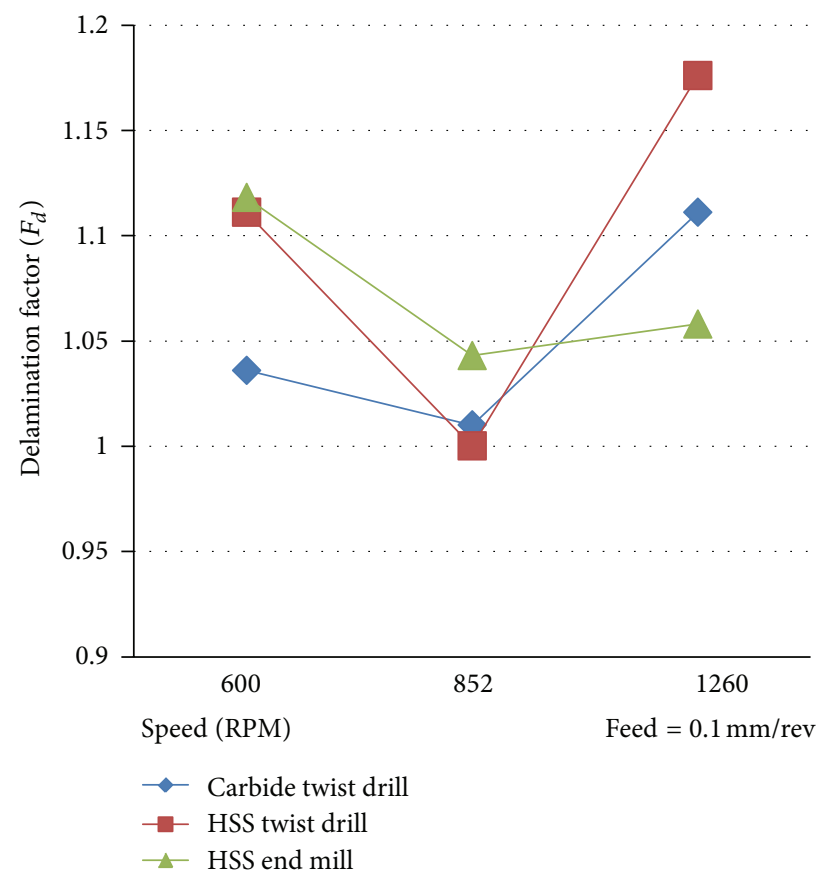

FIGURE 16: Correlation between cutting speed and delamination factor at feed rate of $0.1 \mathrm{~mm} / \mathrm{rev}$.

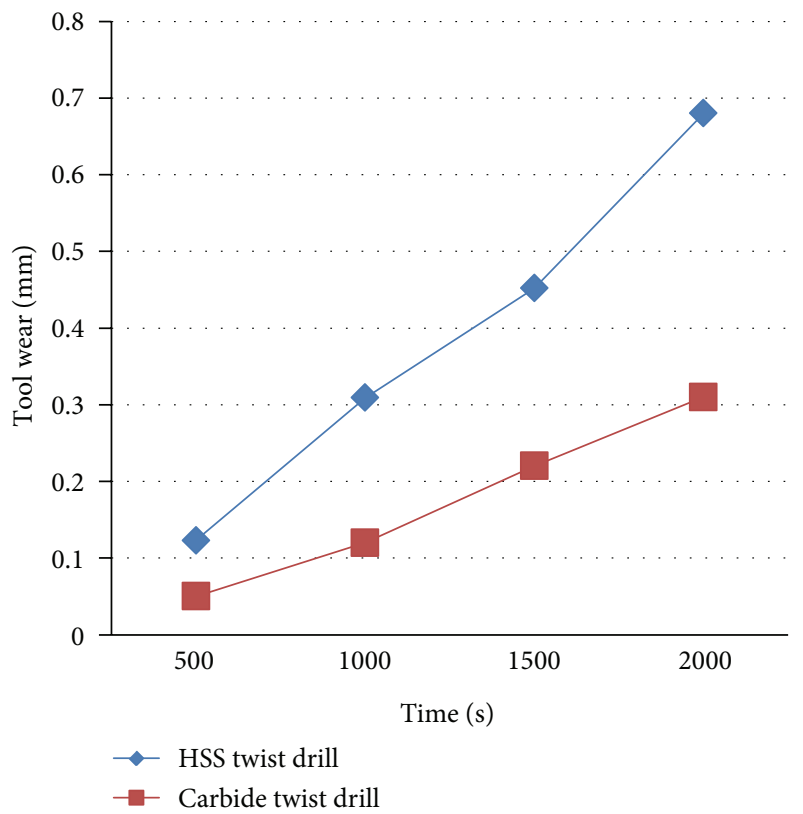

FIGURE 17: Correlation between tool wear and drilling time in hybrid CGRP composites using HSS twist drill and Carbide twist drill.

and HSS end mill, significant delamination is observed in machined coupons.

At cutting speed of $852 \mathrm{rpm}$, the delamination is minimum for HSS at the feed rate of $0.045 \mathrm{~mm} / \mathrm{rev}$. In general, as the feed increases, the delamination must also increase [18], but there are some variations with the carbide and HSS end mill tool. The earlier data depicts that, there is less delamination in CGRP while machined at $852 \mathrm{rpm}$ and $0.1 \mathrm{~mm} / \mathrm{rev}$.

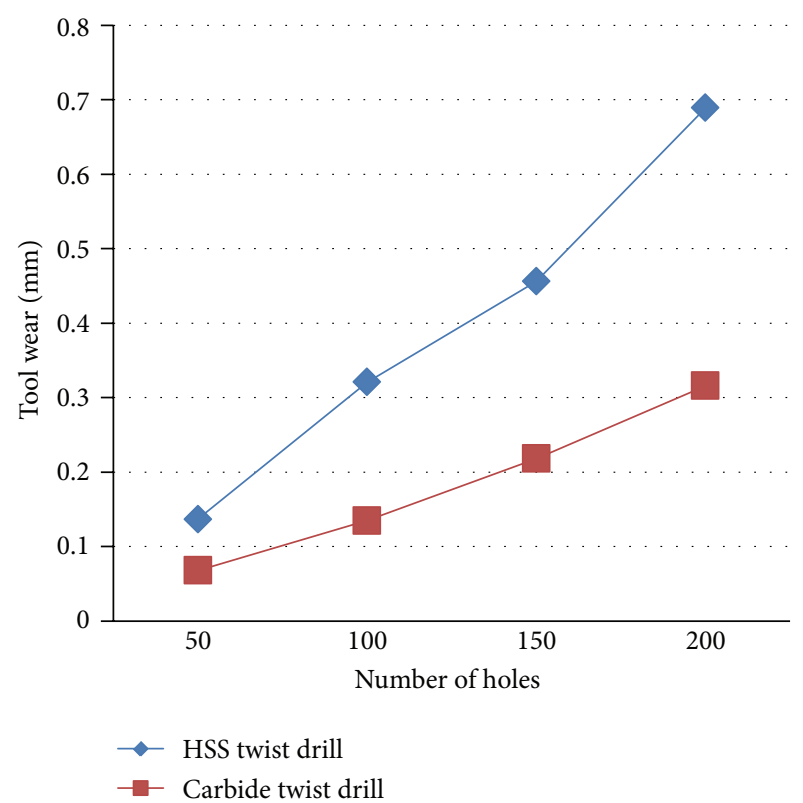

FIGURE 18: Correlation between tool wear and number of holes drilled using HSS twist drill and Carbide twist drill.

Hence, this parameter ( $852 \mathrm{rpm}, 0.1 \mathrm{~mm} / \mathrm{rev}$ ) can be considered as optimum parameter for machining CGRP. However, final confirmation can be obtained after studying its behavior at cutting speed of $1260 \mathrm{rpm}$.

At cutting speed of $1260 \mathrm{rpm}$, the behavior of HSS end mill and carbide tool follows the same trend as discussed earlier (Figure 14). The delamination increases for HSS twist drill as feed increases. In all the three cases of cutting speed (600 rpm, $852 \mathrm{rpm}$, and $1260 \mathrm{rpm}$ ), the delamination increases as feed increases for HSS twist drill, and this is in agreement with the work reported elsewhere [10, 18]. Also, we can say that there is some contribution of thrust force towards this rise in delamination [18] for HSS twist drill.

But behavior of delamination in the case of Carbide tool and HSS end mill also depicts that there is no direct relationship of thrust force with delamination factor [19]. This is not in agreement with the work as suggested by [8].

It was also found that the delamination is comparatively lower for the parameter $(852 \mathrm{rpm}$ and $0.1 \mathrm{~mm} / \mathrm{rev}$.) (Figure 13). Simultaneously, it also exhibits low thrust force for this parameter. Hence, this may be considered as optimum parameter for future studies.

3.5.2. Effect of Cutting Speed on Delamination. The effect of cutting speed on delamination is shown in Figures 15 and 16. In Figure 15, the delamination is minimum for HSS twist drill at the speed of $852 \mathrm{rpm}$ at a feed rate of $0.045 \mathrm{~mm} / \mathrm{rev}$. The delamination decreases as speed increases initially, and later it rises to the maximum value. Similar kind of behavior was reported elsewhere [9].

In Figure 16, delamination is less for all the tools at the speed of $852 \mathrm{rpm}$. The best minimum delamination value is registered for HSS twist drill and for Carbide tool at the speed of $852 \mathrm{rpm}$ and feed rate of $0.1 \mathrm{~mm} / \mathrm{rev}$. At $852 \mathrm{rpm}$, the 


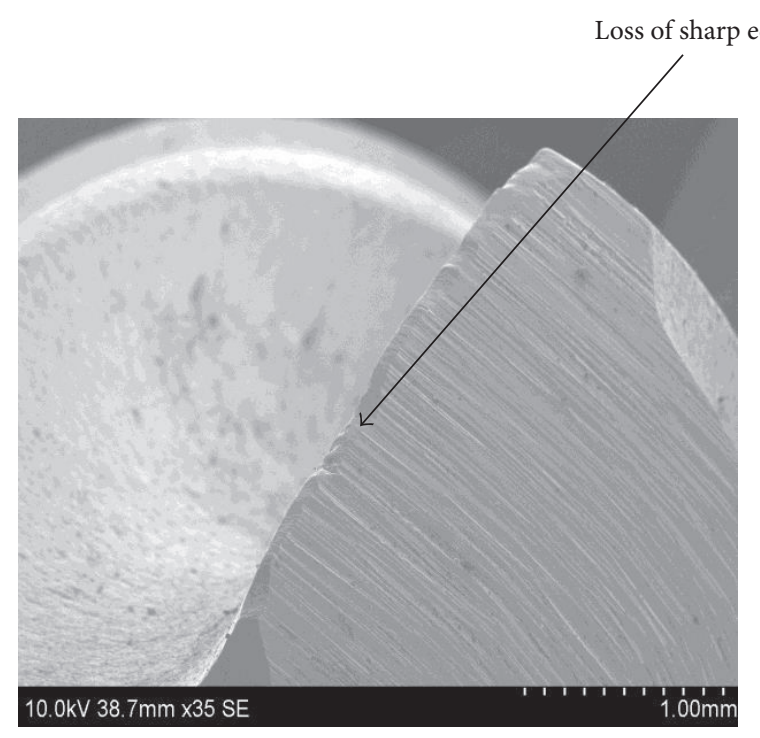

(a)

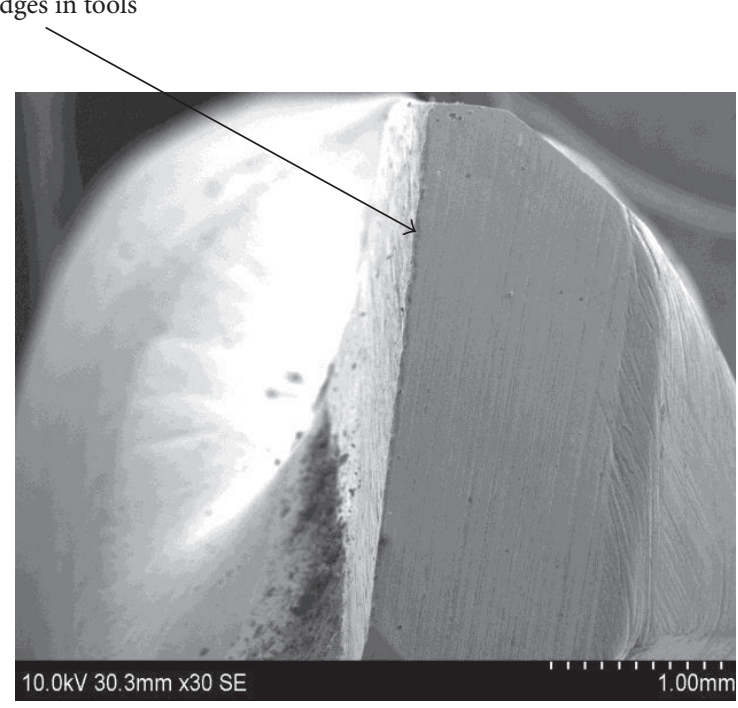

(b)

FIGURE 19: Wear surfaces of (a) HSS twist drill; (b) Carbide tool drill after machining 200 holes in hybrid CGRP composites.

drill may exert sufficient cutting force on the CGRP samples during machining and also shave the fibres easily at that optimum speed. The vibration level during machining may be low, which could be also a possible reason for reduced delamination at this speed. At higher speed (1260 rpm), the cutting force required may not be optimum; also, the vibration of the drill at higher speed may be an indirect reason for increase in delamination. To analyze this, a detailed study may be required to corroborate the machine tool structure with the vibration level and the drilling speed, which may be discussed in further articles.

Thus, cutting speed of $852 \mathrm{rpm}$ and feed rate of $0.1 \mathrm{~mm} /$ rev can be considered as an optimum parameter in drilling CGRP using Carbide tool and HSS twist drill. But final conclusion about the tool material can be arrived at only by considering the tool wear and tool life.

3.6. Tool Wear Studies. 200 holes are drilled on CGRP using HSS twist drill and carbide tool at a cutting speed of 852 rpm and feed of $0.1 \mathrm{~mm} / \mathrm{rev}$. The tool wear is measured in intervals of $25,50,75,100,125,150,175$, and 200 holes. The tool wear was measured using tool maker's microscope and plotted in Figures 17 and 18. It was found that the tool wear increases as drilling time increases. In other words, the tool wear increases proportionally as the number of holes drilled increases (Figures 17 and 18). Similar kind of observation is reported elsewhere $[9,12]$. It is also observed that the wear rate of carbide tool is comparatively smaller than the HSS twist drill for drilling the equal number of holes.

Carbide tool being harder than HSS twist drill can effectively resist wear than HSS tool. This excessive thrust force developed by the presence of nanoclay in the polyester matrix can also accelerate the tool wear in HSS twist drill and hence its life also gets reduced. The tool wear can be identified by the SEM micrographs shown in Figure 19. It was found that the HSS tool loses its sharp edges more significantly than the Carbide tool. The HSS being softer compared to Carbide could be the reason for the early loss of its sharp edge during machining CGRP. Hence, we can identify that CGRP can be machined effectively with good surface finish and less delamination by consuming less power at a feed rate of $0.1 \mathrm{~mm} / \mathrm{rev}$ and at a cutting speed of $852 \mathrm{rpm}$ using carbide tool, which will lead to better tool life as well.

\section{Conclusions}

The experimental results confirm that the presence of nanoclay in polyester matrix of hybrid CGRP nanocomposites is influencing the thrust force developed during drilling. It was also found that, irrespective of the tool used, the delamination factor is low for the optimum cutting speed of $852 \mathrm{rpm}$ and feed rate of $0.1 \mathrm{~mm} / \mathrm{rev}$. The CGRP machined by carbide twist drill at this optimum parameter also registers low thrust force and less delamination factor. Hence, it can be concluded by stating that the hybrid nanoclay and glass fibre reinforced polyester composites (CGRP) can be drilled efficiently with less power consumption and less delamination by using carbide twist drill at the cutting speed of $852 \mathrm{rpm}$ and feed rate of $0.1 \mathrm{~mm} / \mathrm{rev}$. The tool wear of carbide tool is low compared with HSS twist drill.

Glass fibre reinforced polyester composites (GRP) and hybrid nanoclay and glass fibre reinforced polyester nanocomposites (CGRP) are fabricated by vacuum assisted resin infusion technique. The optimum mechanical properties are obtained for CGRP with $3 \mathrm{wt}$ \% nanoclay. Three types of drills (carbide twist drill D 5407060, HSS twist drill BS-328, and HSS end mill (4 flutes "N"-type end mill RH-helical flute)) of $6 \mathrm{~mm}$ diameters are used to drill holes on GRP and CGRP. Three different speeds $(600,852$, and $1260 \mathrm{rpm})$ and two different feeds $(0.045,0.1 \mathrm{~mm} / \mathrm{rev})$ are selected as process 
parameters. The effect of process parameter on thrust force and delamination during drilling CGRP is analyzed for optimizing the machining parameters. The delamination factor is low for the optimum process parameter (feed $=0.1 \mathrm{~mm} / \mathrm{rev}$ and speed $852 \mathrm{rpm}$ ). Microstructural analysis confirms that at higher feeds, delamination is low for CGRP drilled with carbide tools. In order to analyze the effect of nanoclay in CGRP on tool wear, 200 holes were drilled on CGRP samples with 3 wt.\% nanoclay, and the tool wear is analyzed under optimized parametric condition. Tool wear is high in HSS twist drill compared with carbide drill. The presence of nanoclay also accelerates the tool wear.

\section{References}

[1] X. Kornmann, L. A. Berglund, J. Sterte, and E. P. Giannelis, "Nanocomposites based on montmorillonite and unsaturated polyester," Polymer Engineering and Science, vol. 38, no. 8, pp. 1351-1358, 1998.

[2] B. Lepoittevin, N. Pantoustier, M. Devalckenaere et al., "Polymer/layered silicate nanocomposites by combined intercalative polymerization and melt intercalation: a masterbatch process," Polymer, vol. 44, no. 7, pp. 2033-2040, 2003.

[3] R. K. Bharadwaj, A. R. Mehrabi, C. Hamilton et al., "Structureproperty relationships in cross-linked polyester-clay nanocomposites," Polymer, vol. 43, no. 13, pp. 3699-3705, 2002.

[4] P. Jawahar, R. Gnanamoorthy, and M. Balasubramanian, "Tribological behaviour of clay-thermoset polyester nanocomposites," Wear, vol. 261, no. 7-8, pp. 835-840, 2006.

[5] P. Jawahar and M. Balasubramanian, "Thermal, mechanical and water barrier properties of clay-polyester nanocomposites," International Journal of Plastics Technology, vol. 9, no. 2, pp. 472481, 2005.

[6] P. Jawahar and M. Balasubramanian, "Influence of nanosize clay platelets on the mechanical properties of glass fiber reinforced polyester composites," Journal of Nanoscience and Nanotechnology, vol. 6, no. 12, pp. 3973-3976, 2006.

[7] A. Velayudham, R. Krishnamurthy, and T. Soundarapandian, "Evaluation of drilling characteristics of high volume fraction fibre glass reinforced polymeric composite," International Journal of Machine Tools and Manufacture, vol. 45, no. 4-5, pp. 399406, 2005.

[8] H. Hocheng and C. C. Tsao, "Effects of special drill bits on drilling-induced delamination of composite materials," International Journal of Machine Tools and Manufacture, vol. 46, no. 12-13, pp. 1403-1416, 2006.

[9] S. Arul, L. Vijayaraghavan, S. K. Malhotra, and R. Krishnamurthy, "The effect of vibratory drilling on hole quality in polymeric composites," International Journal of Machine Tools and Manufacture, vol. 46, no. 3-4, pp. 252-259, 2006.

[10] U. A. Khashaba, "Delamination in drilling GFR-thermoset composites," Composite Structures, vol. 63, no. 3-4, pp. 313-327, 2004.

[11] N. S. Mohan, S. M. Kulkarni, and A. Ramachandra, "Delamination analysis in drilling process of glass fiber reinforced plastic (GFRP) composite materials," Journal of Materials Processing Technology, vol. 186, no. 1-3, pp. 265-271, 2007.

[12] M. Rahman, S. Ramakrishna, J. R. S. Prakash, and D. C. G. Tan, "Machinability study of carbon fiber reinforced composite," Journal of Materials Processing Technology, vol. 89-90, pp. 292297, 1999.
[13] R. Magaraphan, W. Lilayuthalert, A. Sirivat, and J. W. Schwank, "Preparation, structure, properties and thermal behavior of rigid-rod polyimide/montmorillonite nanocomposites," Composites Science and Technology, vol. 61, no. 9, pp. 1253-1264, 2001.

[14] B. Wetzel, F. Haupert, and M. Q. Zhang, "Epoxy nanocomposites with high mechanical and tribological performance," Composites Science and Technology, vol. 63, no. 14, pp. 2055-2067, 2003.

[15] J. Y. Lee and H. K. Lee, "Characterization of organobentonite used for polymer nanocomposites," Materials Chemistry and Physics, vol. 85, no. 2-3, pp. 410-415, 2004.

[16] J. H. Park and S. C. Jana, “The relationship between nano- and micro-structures and mechanical properties in PMMA-epoxynanoclay composites," Polymer, vol. 44, no. 7, pp. 2091-2100, 2003.

[17] J. P. Davim, P. Reis, and C. C. António, "Experimental study of drilling glass fiber reinforced plastics (GFRP) manufactured by hand lay-up," Composites Science and Technology, vol. 64, no. 2, pp. 289-297, 2004.

[18] A. T. Marques, L. M. Durão, A. G. Magalhães, J. F. Silva, and J. M. R. S. Tavares, "Delamination analysis of carbon fibre reinforced laminates: evaluation of a special step drill," Composites Science and Technology, vol. 69, no. 14, pp. 2376-2382, 2009.

[19] A. M. Abrão, J. C. C. Rubio, P. E. Faria, and J. P. Davim, “The effect of cutting tool geometry on thrust force and delamination when drilling glass fibre reinforced plastic composite," Materials and Design, vol. 29, no. 2, pp. 508-513, 2008. 

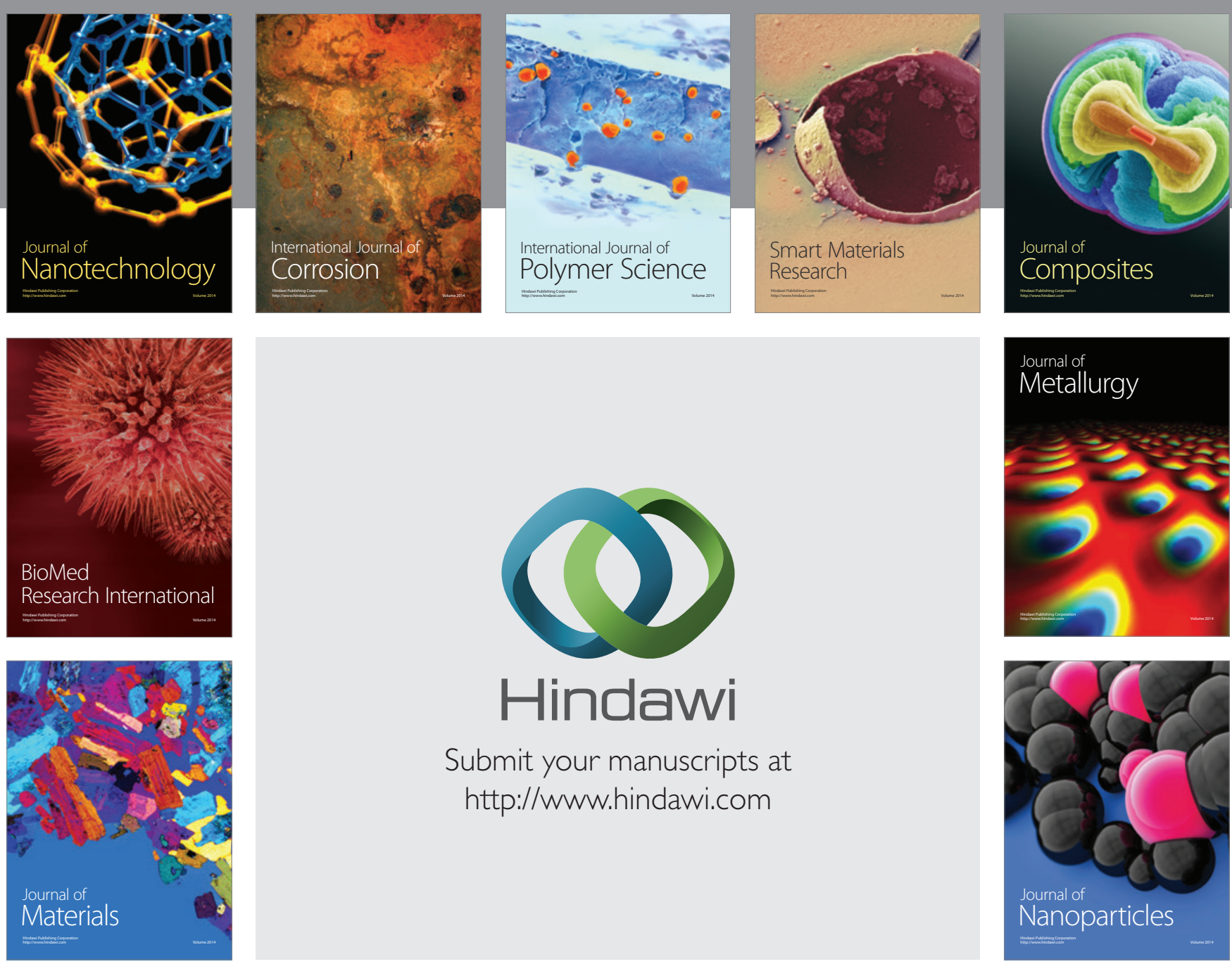

Submit your manuscripts at http://www.hindawi.com
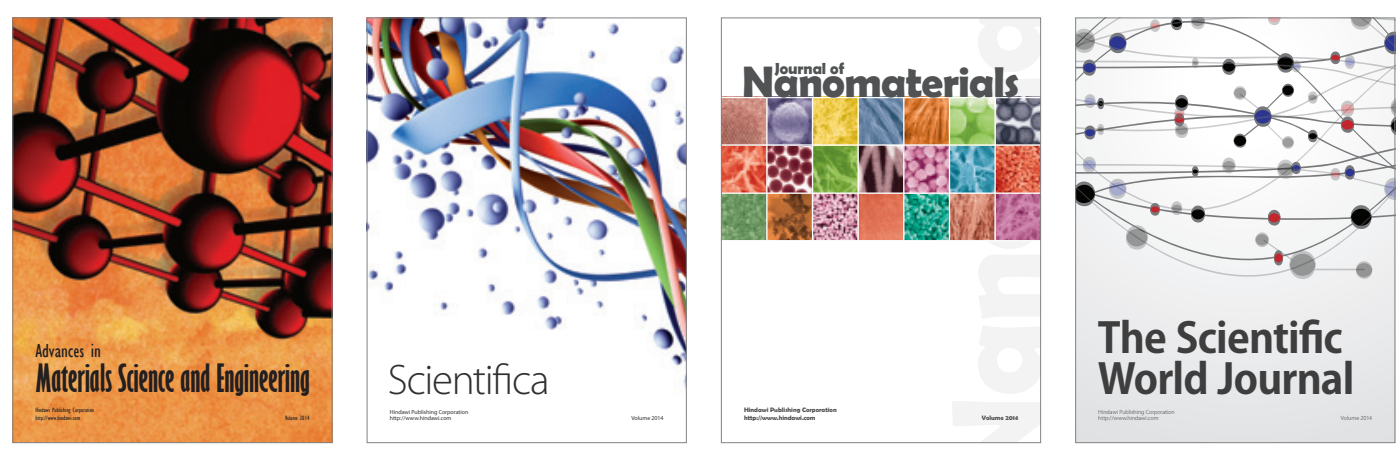

\section{The Scientific World Journal}
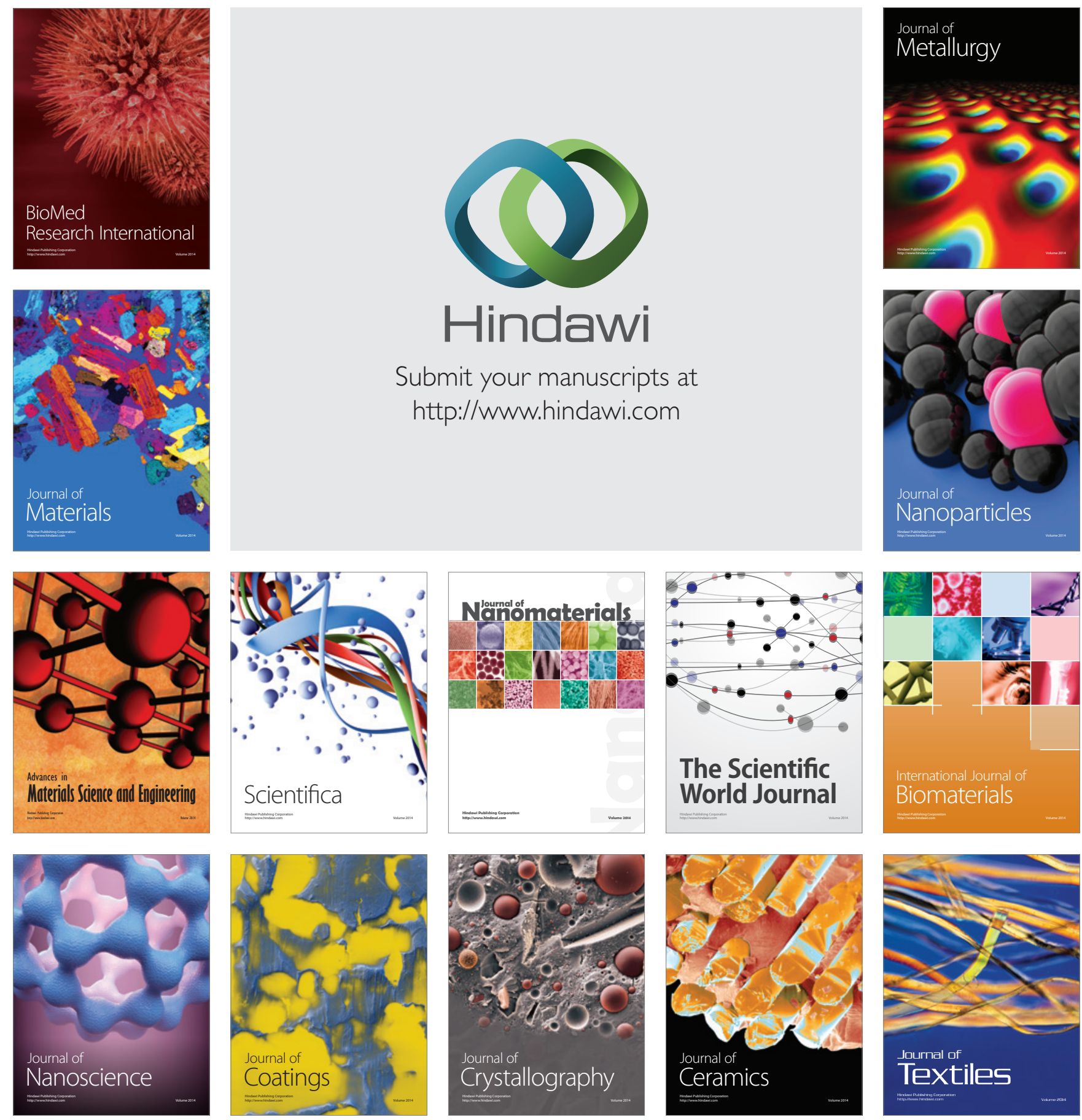